\title{
A Study of PA DNA/Dendron Nanoparticles for Genetic Immunisation Against Anthrax
}

\author{
Suzie. J. Ribeiro ${ }^{1}$, Sjoerd. G. Rijpkema*, ${ }^{2}$, Zarmina Durrani ${ }^{2}$ and A. T. Florence ${ }^{1}$ \\ ${ }^{I}$ Centre for Drug Delivery Research, The School of Pharmacy, University of London, 29/39 Brunswick square, London, \\ WCIN $1 A X$ and ${ }^{2}$ Division of Bacteriology, National Institute for Biological Standards and Control, South Mimms, Pot- \\ ters Bar, EN6 $3 Q G$
}

\begin{abstract}
Protective antigen (PA), the binding subunit of toxins produced by Bacillus anthracis is singularly the most important antigen required for specific immunity to anthrax disease. We used cationic poly-lysine dendrons to develop a genetic anthrax vaccine. Plasmid CMV/ER PA83 which encoded full length PA 83 was complexed with dendrons to form dendriplexes. Two types of dendron were used: $\mathrm{C}_{0}$ and $\mathrm{C}_{18}$. These were mixed with DNA to form dendriplexes, of approximately $80 \mathrm{~nm}$ in size, which were tested for immunogenicity. A/J and BALB/c mice were vaccinated with dendriplexes containing $1 \mu \mathrm{g}$ and $50 \mu \mathrm{g}$ plasmid DNA per dose over a period of 6 weeks. Immunisation with naked PA DNA did not induce an antibody response even after secondary boosting, whereas both dendriplexes produced strong anti-PA antibody response. This response was dose dependent. We conclude that dendriplexes show superior immunogenicity compared to naked PA DNA in both mouse strains and that $\mathrm{C}_{18}$ dendriplexes with $50 \mu \mathrm{g}$ plasmid DNA are most efficacious. However, the elicited antibodies did not neutralise lethal toxin in vitro. Therefore further work is required to improve these preparations in order to elicit functional antibodies.
\end{abstract}

Key Words: Nanoparticle, dendron, dendriplexes, DNA vaccines, protective antigen.

\section{INTRODUCTION}

Anthrax has become an important area of research due to recent bioterrorism activities and a heightened interest in anthrax pathogenesis, immunity, and vaccine development has ensued since. The virulence of Bacillus anthracis is due to the production of three-component toxin, which consists of protective antigen (PA, binding subunit) and either lethal factor (LF, catalytic subunit) or oedema factor (EF, catalytic subunit). PA first cloned in 1986 provides protective immunity $[1,2]$.

The existing anthrax vaccines, the American anthrax vaccine adsorbed (AVA) and the British anthrax vaccines precipitated (AVP), are protective but have some disadvantages because they cause side effects and are poorly defined. Besides PA, these vaccines contain other antigens, for example LF and EF for AVP, although only trace amounts of LF were found for AVA [3]. In the case of AVP other antigens not related to anthrax toxins, such as S-layer proteins, and heat shock proteins have also been detected [4]. These limitations have raised interest in the development of a new generation of anthrax vaccines. The majority of reported work aimed at treating or preventing anthrax has centred on PA, predominantly for its ability to mediate intoxication [5-7]. These observations have increased focus on the induction of toxin neutralising antibodies (TNAs) either by recombinant PA (rPA) vaccines or by experimental genetic vaccines consisting of full length and truncated forms of PA [8]. Poor

*Address correspondence to this author at the Division of Bacteriology, National Institute for Biological Standards and Control, South Mimms, Potters Bar, EN6 3QG; E-mail: srijpkema@nibsc.ac.uk immunogenicity of naked DNA has been mitigated by the use of cationic lipids such as Vaxfectin and PLGA particles as delivery vehicles for DNA vaccines $[9,10]$. In addition, new vaccination strategies have been designed to improve compliance by reducing the dosage and the number of immunisations required [11].

We used poly-lysine dendrons to embed PA plasmid DNA in small compact particles named dendriplexes to improve the immunogenicity of the DNA vaccine [12]. A dendron is a structurally controlled fragment of a dendrimer and these are also known as partial dendrimers. A dendron can be divided into three different regions: the core, the branches, and periphery groups similar to the full dendrimer structure [13]. The number of branching groups encountered upon moving outward from the dendron core defines its generation (G-1, G-2, G-3), containing less end groups compared to its parent dendrimer even at the highest generation. These distinct regions of the dendron can be manipulated accordingly to the desired characteristics for drug or gene carrier systems. Dendrons can be tailored to meet crucial criteria such as low toxicity, translocation, tissue targeting and permeability especially through cell membranes [14]. Dendrons have a flexible structure allowing localised bending or distortion of DNA, which facilitates the formation of these compact dendriplexes. DNA can, under different conditions, condense into toroids and short rods of varying sizes, which is dependent on the concentration or length of the DNA [15].

Synthetic peptide polymers containing lysine are biocompatible and have been shown to have adjuvant properties: they increase immunogenicity of weak antigens, enhance uptake of antigen in tissues and extend the duration of exposure in the host. For example, Trp-Lys-Tyr-Met-Val-- ${ }^{-}$ 
Met enhanced surface expression of CD80 receptor on mouse bone marrow-derived dendritic cells and stimulated IFN- $\gamma$ production [16]. CD80 is a co-stimulatory signal for the induction of immunity in response to DNA. In addition L-lysine stimulated the antibody response to heat killed $M y$ cobacterium tuberculosis and Bacille Calmette Guerin [17].

We have shown that mice immunised with lysine based dendrons $\mathrm{C}_{0}$ and $\mathrm{C}_{18}$ (Fig. 1) produce antibodies to encapsulated PA-DNA [12].

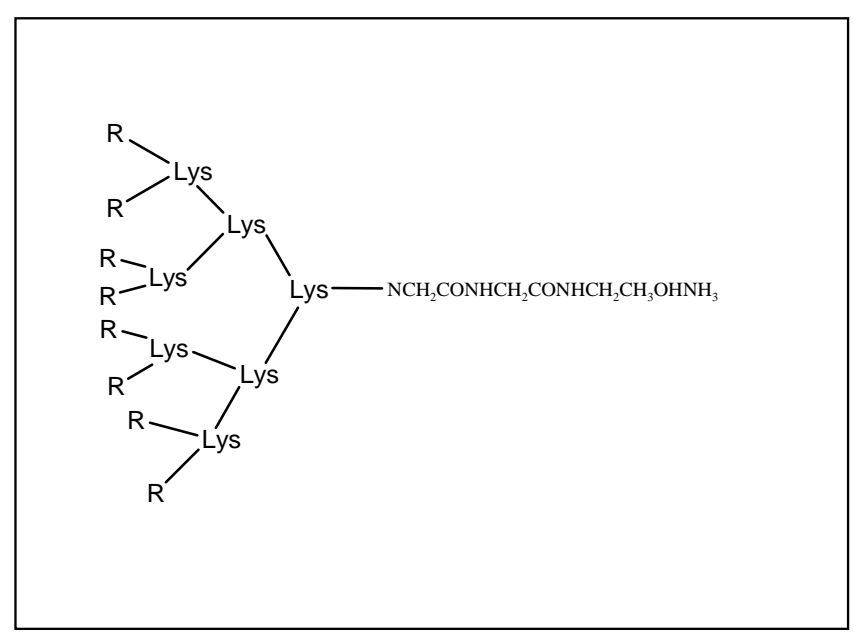

$(\mathrm{C})_{0}(\mathrm{Lys})_{7}\left(\mathrm{NH}_{2}\right)_{8} \quad \mathrm{MW} 1174.91$

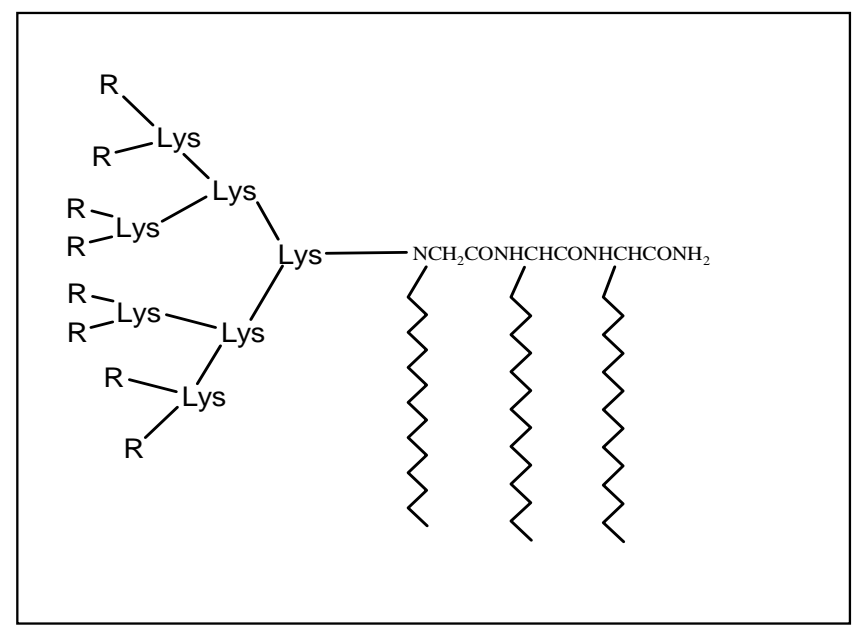

$\left(\mathrm{C}_{18}\right)_{3}(\mathrm{Lys})_{7}\left(\mathrm{NH}_{2}\right)_{8} \quad \mathrm{MW} \mathbf{1 7 5 8 . 4 5}$

Fig. (1). Simplified structure of the cationic lysine-based dendrons $\mathrm{C}_{0}\left[(\mathrm{C})_{0}(\mathrm{Lys})_{7}\left(\mathrm{NH}_{2}\right)_{8}\right]$ with a $\mathrm{MW}$ of 1174.91 and $\mathrm{C}_{18}\left[\left(\mathrm{C}_{18}\right)_{3}\right.$ (Lys) $)_{7}\left(\mathrm{NH}_{2}\right)_{8}$ ] with a MW of 1758.45 . Both dendrons contain 16 amino groups of which seven lysine groups (=L) are attached to the core.

In the current study, we extend these findings and examine whether the incorporation of different amounts of PA DNA in $\mathrm{C}_{0}$ and $\mathrm{C}_{18}$ dendriplexes improves the acquired immune response in $\mathrm{BALB} / \mathrm{c}$ and $\mathrm{A} / \mathrm{J}$ mice.

\section{MATERIALS AND METHODS}

\subsection{PA-Expression DNA Plasmid}

DNA encoding full length PA (PA83) was cloned into the eukaryotic expression plasmid, pCMV/ER, containing an endoplasmatic reticulum retention signal for PA [18]. The pCMV/ER vector without the PA83 insert was used as negative control throughout the study. Plasmids were purified as described [18].

\subsection{Synthesis of the Dendrons}

Two dendrons were synthesized by stepwise solid-phase peptide synthesis from Boc-Lys(Boc)-OH and 2-amino octadecanoic acid for $\mathrm{C}_{18}$ dendron and Boc-Ala-OH for $\mathrm{C}_{0}$ dendron (Novabiochem) on 4-methyl benzhydrylamine resin using the Boc-strategy [19]. The $\mathrm{C}_{0}$ dendron $\left[(\mathrm{C})_{0}(\mathrm{Lys})_{7}\right.$ $\left(\mathrm{NH}_{2}\right)_{8}$ ] contains seven lysine groups and eight amino groups attached to the core and the $\mathrm{C}_{18}$ dendron $\left[\left(\mathrm{C}_{18}\right)_{3}(\mathrm{Lys})_{7}\left(\mathrm{NH}_{2}\right)_{8}\right]$ contains an additional three hydrocarbon chains. Structures are given in Fig. (1).

\subsection{Preparation of PA DNA and Control Dendriplexes}

The dendriplexes were formed by addition of equal volumes of DNA and dendron while stirring. These complexes were allowed to equilibrate for $30 \mathrm{mins}$ prior to analysis. Complexes were prepared in double distilled de-ionised water unless otherwise noted. A 10:1 molar charge ratio (dendron:DNA) was used in both sets of dendriplexes as this specific stoichiometric ratio condenses the DNA more efficiently to produce small particles with a narrow polydispersity.

\subsection{Characterisation of Dendriplex Particles}

The sizes of the PLGA-dendriplex and dendriplex particles, all with a diameter of $<1 \mu \mathrm{m}$, were determined by photon correlation spectroscopy using a Zetasizer 3000 (Malvern Instruments, Malvern, UK, He-Ne laser, $90^{\circ}$ angle of measurement) after dilution of samples. The results of three measurements are expressed as the Z-average $(\mathrm{nm}) \pm \mathrm{SD}$ and average zeta potential $(\mathrm{mV}) \pm \mathrm{SD}$.

\subsection{Transmission Electron Microscopy}

Transmission electron microscopy was used to examine the structure of dendriplexes. Specimens were prepared by depositing a small droplet of complex suspension on a copper grid (Gilder, Grantham, UK). The samples were stained with $1 \%$ uranyl acetate and viewed under a Philips 201L electron microscope.

\subsection{Immunisation of Animals}

Mouse strains $\mathrm{BALB} / \mathrm{c}$ and $\mathrm{A} / \mathrm{J}$ were used in the low dose study and only BALB/c mice were used in the high dose study. All mice were female and weighed 16-20 g. In the low dose study, mice received an injection with dendriplexes containing $1 \mu \mathrm{g}$ of DNA. In the high dose study, dendriplexes with $50 \mu \mathrm{g}$ DNA were administered per mouse. The dendriplexes were suspended in PBS, and $20 \mu 1$ was injected intramuscularly (i.m.) into the thigh using a Hamilton syringe. No additional excipients or adjuvants (e.g. alum) were added to DNA-dendriplex or dendriplex mixtures. In the low dose study, 5 animals received either $\mathrm{C}_{18}$ or $\mathrm{C}_{0}$ dendriplexes. The high dose experiment was carried out with 15 animals per group receiving either $\mathrm{C}_{18}$ or $\mathrm{C}_{0}$ dendrons. Two booster vaccinations were given every 3 weeks and tail vein blood was taken from each mouse. Terminal bleeds were collected at week 9 . Serum was stored at $-20{ }^{\circ} \mathrm{C}$ until further use. 


\subsection{Measurement of Anti-PA Antibody Levels in Serum}

Serum samples of individual mice were analysed by enzyme immunosorbent assay for anti-PA antibodies. All washing steps were carried out with PBS containing $0.05 \%$ Tween 20 (PBST). Each incubation step was carried out at room temperature, if not indicated otherwise. The 96 wells of high-binding protein microtiter plates (MaxiSorp $^{\mathrm{TM}}$, Nunc) were each coated with $100 \mu 15 \mu \mathrm{g} \mathrm{ml}^{-1}$ of rPA (List Biologicals, Quadratech, Epsom, UK) in a $0.05 \mathrm{M}$ carbonate buffer at $\mathrm{pH} 9.5$ (at $4{ }^{\circ} \mathrm{C}$ overnight). The wells were washed and blocked with $200 \mu \mathrm{l} /$ well of $2 \%$ skimmed milk powder in PBST for $2 \mathrm{~h}$. Each serum sample was diluted starting with a 10-fold dilution, doubling across the plate and incubated for $2 \mathrm{~h}$. The wells were washed extensively with PBST and anti-PA antibodies were detected by using goat antimouse IgG (Sigma). Biotinylated anti-mouse IgG1 and IgG2a (Pharmingen) were used to detect anti-PA antibodies of these subclasses. In this case bound secondary antibody was detected by adding streptavidin peroxidase (Sigma). TMBlue $(100 \mu \mathrm{l})$ was added to each well and the reaction was stopped after 5 min with $25 \mu 12 \mathrm{M} \mathrm{H}_{2} \mathrm{SO}_{4}$. Optical densities were read at $450 \mathrm{~nm}$. A negative serum pool and a positive serum pool were included on each plate.

\subsection{Toxin Neutralisation Assay}

The toxin neutralisation assay was carried out as described by Hering et al. with slight modifications [20]. Toxin neutralising antibody (TNA) titers were determined by the ability of serum samples to protect the RAW 264.7 cells from the effect of lethal toxin (LT), a cocktail of $0.10 \mu \mathrm{g} \mathrm{ml}^{-1}$ rPA and $0.08 \mu \mathrm{g} \mathrm{ml}^{-1} \mathrm{rLF}$ (both from List Biological Laboratories). Cells were grown overnight in 96 well plates (Costar Corning Incorporated, Corning, NY) and were maintained in Dulbecco's Minimal Essential Medium (D-MEM) containing $5 \%$ heat-inactivated fetal calf serum. Mouse serum samples were doubly diluted in cell culture medium, starting with a dilution of 1:100. Serum dilutions were pre-incubated with LT in a humidified incubator at $37^{\circ} \mathrm{C}$ for $1 \mathrm{~h}$. Medium as well as detached RAW 264.7 cells were removed from wells and replaced with preincubated immune serum and LT. Wells containing medium only or LT and medium served as controls. Each serum dilution was tested in triplicate. After incubating for $3 \mathrm{~h}, 10 \mu \mathrm{lWST}-1$ reagent (Roche) was added to each well and incubated for $4 \mathrm{~h}$ at $37^{\circ} \mathrm{C}$. The absorbance was then read at $450 \mathrm{~nm}$.

\subsection{Statistical Analysis}

Anti-PA antibody and TNA titers of different treatment groups were compared, using a paired Student's $t$-test and one-way ANOVA with pairwise comparisons, where a significant difference was observed stated in both cases as $p<0.05$.

\section{RESULTS AND DISCUSSION}

We investigated dendriplexes as an alternative vehicle to deliver DNA vaccines. Dendriplexes have several advantages; e.g. they protect DNA from degradation and the small peptides, embedded in the dendrons, have the potential to act as adjuvants. Two types of dendrons were used to produce dendriplexes: $(\mathrm{C})_{0}(\mathrm{Lys})_{7}\left(\mathrm{NH}_{2}\right)_{8}$ named $\mathrm{C}_{0}$ and $\left(\mathrm{C}_{18}\right)_{3} \mathrm{Lys}_{15}$ $\left(\mathrm{NH}_{2}\right)_{16}$ named $\mathrm{C}_{18}$ (Fig. 1). An electron micrograph substan- tiates that these particles are small dense spherical compact structures of approximately $80 \mathrm{~nm}$ in size (Fig. 2).

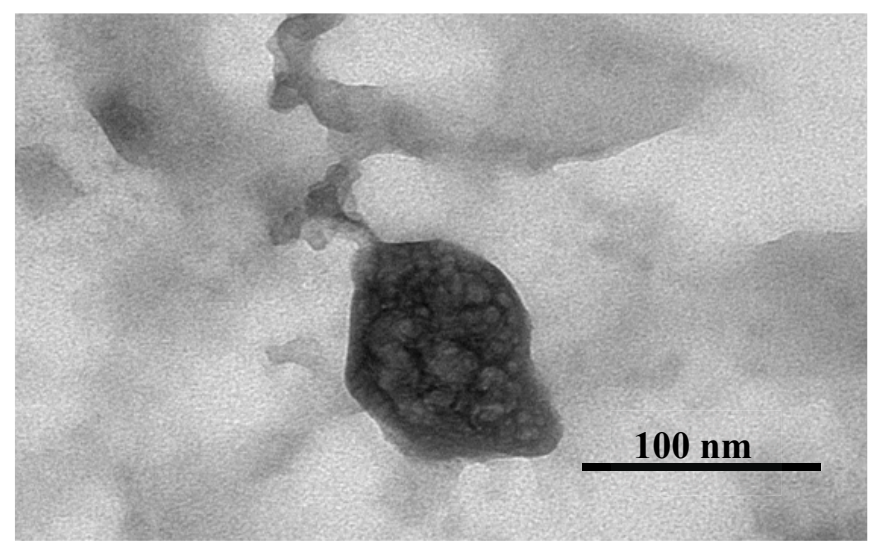

Fig. (2). Cryo-transmission electron microscopy of a $\mathrm{C}_{18}$ dendriplex containing $50 \mu \mathrm{g}$ pCMV/ER PA83 negatively stained with $1 \%$ aqueous uranyl acetate.

In a previous study we observed that dendriplexes did improve the immunogenicity of naked PA DNA in BALB/c mice. However TNAs were lacking [12]. Here, we extend these findings by analysis of the antibody response in two strains of mice that had received either low or high doses of PA DNA. Repeated i.m. immunisations with $1 \mu \mathrm{g}$ of naked DNA (low dose) did not induce an anti-PA antibody response in $\mathrm{A} / \mathrm{J}$ mice (data not shown) or BALB/c mice (Fig. 3). These results are in line with our previous findings and corroborate a study by Williamson et al., after two i.m. immunisations with $50 \mu \mathrm{g}$ plasmid DNA containing rPA and/or $\mathrm{rV}$, a surface antigen from Yersinia pestis, a comparatively low immunogenicity and efficacy was observed [12, 21]. Immunisation with dendriplexes induced significantly higher anti-PA antibody responses at a dosage of $1 \mu \mathrm{g}$ DNA per injection (Fig. 3). Surprisingly anti-PA antibody titers fell in both mouse strains following the first booster, previously we did not see this effect with PLGA particles carrying dendrons [12]. The effect may be related to dendrons that carry low amounts of PA DNA and this may make the DNA more susceptible to degradation when compared to DNA packaged in dendrons and PLGA particles thus reducing the booster effect.

After two booster shots, $\mathrm{C}_{18}$ dendriplexes induced a stronger antibody response in $\mathrm{BALB} / \mathrm{c}$ mice than $\mathrm{C}_{0}$ dendriplexes confirming previous observation in this mouse strain [12]. The opposite effect was observed for A/J mice. A second boosting led to an increase in titer and immunisation with $\mathrm{C}_{18}$ dendriplexes produced a superior anti-PA titer in $\mathrm{A} / \mathrm{J}$ mice compared to BALB/c mice (Fig. 3).

The variation in anti-PA IgG response between these two strains following DNA vaccination was also observed by Hahn et al. and can be attributed to differences in the genetic background resulting in altered susceptibility to anthrax toxin $[18,22]$. However, overall titers in mice immunised with dendriplexes were low. Other groups have shown that low antibody titers after priming with PA DNA could be enhanced by a booster with rPA, thus obviating a key advantage of DNA vaccines [23]. Dose dependency of anti-PA antibody production in $\mathrm{A} / \mathrm{J}$ mice has been demonstrated for 
rPA and for PA plasmid DNA [22, 24]. Consequently we sought to improve the antibody response by increasing the amount of PA plasmid DNA in the dendriplexes allowing a dose of $50 \mu \mathrm{g}$ DNA per injection.
Immunisations with $50 \mu \mathrm{g}$ naked DNA (high dose) did not induce a significant anti-PA response after 9 weeks (Fig. 4). After the first booster shot, dendriplexes comprising 50 $\mu \mathrm{g}$ PA plasmid DNA showed a higher level of anti-PA anti-

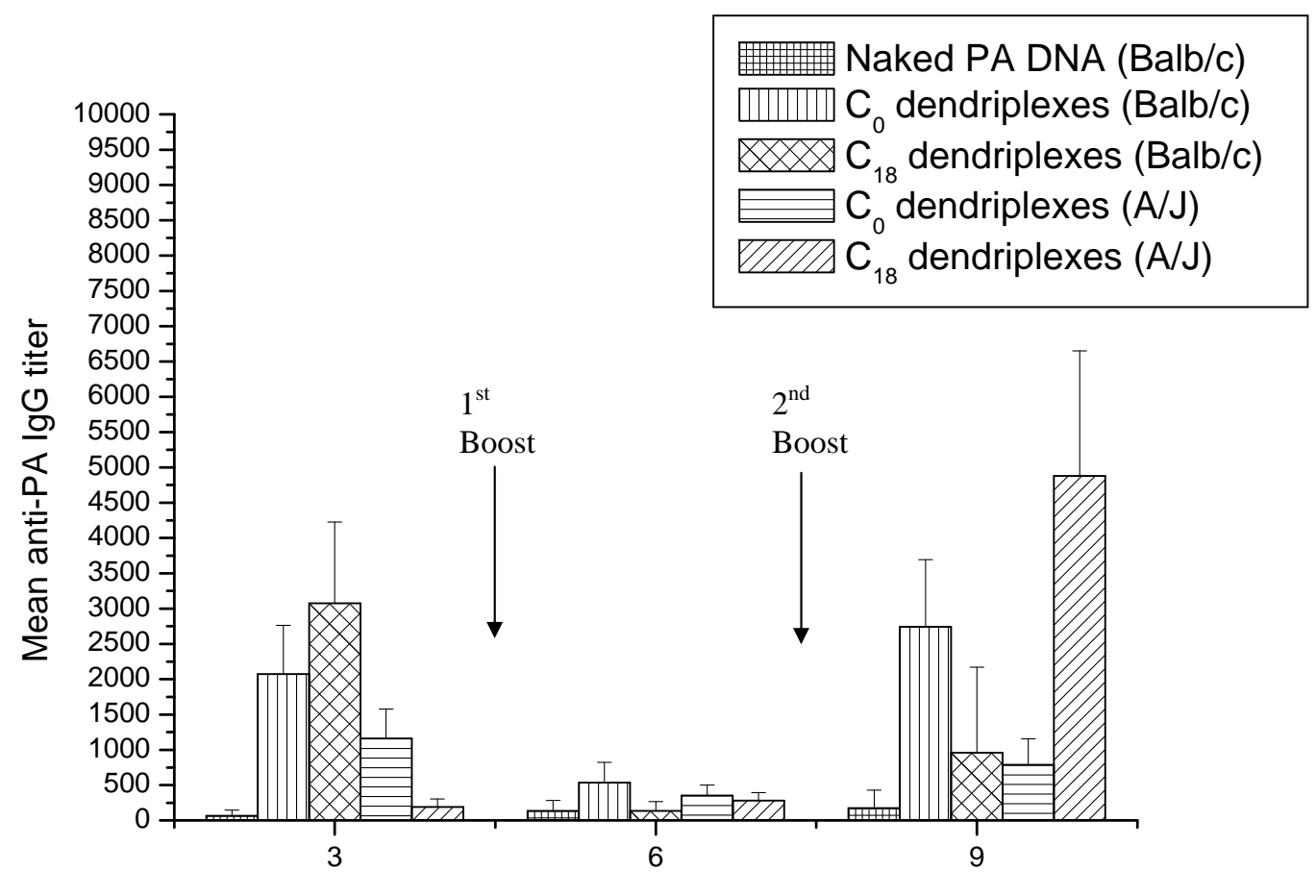

Number of weeks from initial immunisation

Fig. (3). Mean anti-PA titer in sera of BALB/c and A/J mice immunised with $\mathrm{C}_{0}$ dendriplexes and $\mathrm{C}_{18}$ dendriplexes containing $1 \mu \mathrm{g}$ of pCMV/ER PA83, or immunised with naked pCMV/ER PA83. Bars represent SD of five animals.

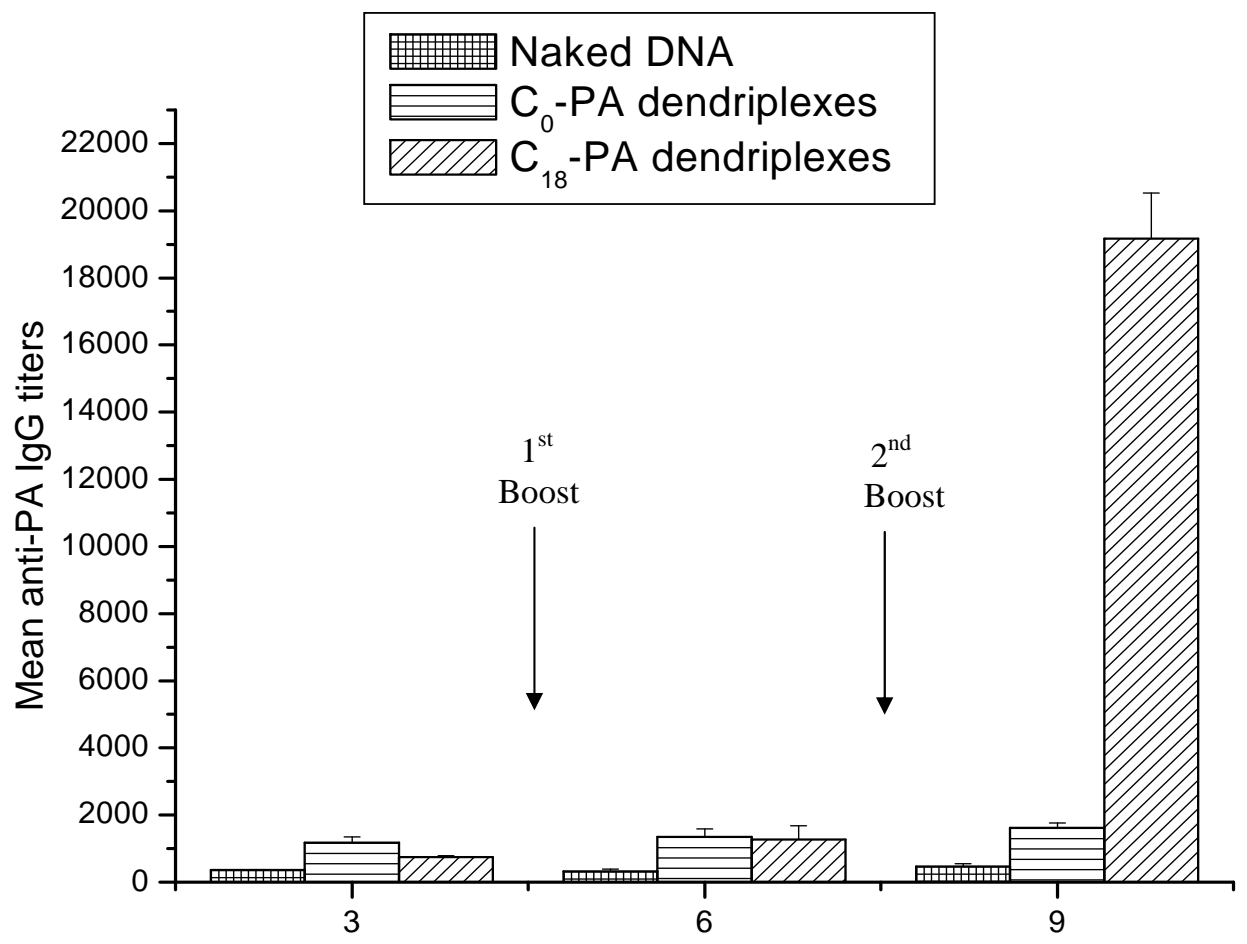

Number of weeks from initial immunisation

Fig. (4). Mean anti-PA $\mathrm{IgG}$ antibody levels in BALB/c mice immunised with $\mathrm{C}_{0}$ dendriplexes, and $\mathrm{C}_{18}$ dendriplexes containing $50 \mu \mathrm{g}$ of pCMV/ER PA83 or naked pCMV/ER PA83. Bars represent SD of five animals. 
bodies compared to immunisations with dendriplexes containing $1 \mu \mathrm{g}$ PA plasmid DNA (Fig. $4 ; p<0.05$ ). There was no significant difference between $\mathrm{C}_{0}$ and $\mathrm{C}_{18}$ dendriplexes (Fig. 4). However at week 9, antibody levels increased substantially ( 18 fold) in mice immunised with $\mathrm{C}_{18}$ dendriplexes. In contrast the antibody response in mice immunised with $\mathrm{C}_{0}$ dendriplexes had levelled off $(p<0.05)$. Thus in BALB/c mice a superior antibody response is induced by two booster shots of $50 \mu \mathrm{g}$ DNA embedded in $\mathrm{C}_{18}$ dendriplexes.

Individual sera were assayed for antigen-specific IgG1 and $\operatorname{IgG} 2 \mathrm{a}$ to evaluate the antibody subclass response after immunisation with $\mathrm{C}_{0}$ and $\mathrm{C}_{18}$ dendriplexes containing $50 \mu \mathrm{g}$ PA plasmid DNA. Immunisation with both dendriplexes induced predominantly IgG1 (Fig. 5). The anti-PA specific IgG1 responses of mice immunised with $\mathrm{C}_{18}$ dendriplexes were higher, but not significantly different from anti-PA IgG1 responses in mice vaccinated with $\mathrm{C}_{0}$ dendriplexes. These results are consistent with the Th2-type immune response following DNA vaccination by gene gun [18]. Indeed, Gu et al. showed that PA DNA vaccination induced IL-4 resulting in a switch to IgG1 [25].

Thus the immune response elicited by immunisation with PA DNA embedded in dendriplexes is dose dependent and has a Th2 bias in BALB/c mice.

The toxin neutralisation assay did not reveal TNAs in sera from mice immunised with high dose PA DNA dendriplexes (results not shown). Therefore immunisation with dendriplexes is likely to fail in protecting mice against anthrax infection. The lack of TNA induction after immunisation with dendriplexes could be due to the choice of animal model or the route of immunisation. Welkos and Friedlander suggested that antitoxin immunity is not protective in mice, although it is effective in non-human primates and rabbits [22]. Indeed the role antibodies play in vaccine induced resistance to anthrax infection is not considered to be well defined [7]. Only a proportion of mice genetically immunised by gene gun developed low levels of TNAs and these were not associated with protection [18]. Further work by Hahn et al. showed that gene gun inoculation of $3 \mu \mathrm{g}$ of a mixture of two plasmid constructs containing the PA gene, including pCMV/ER PA83, did induce a good antibody response in mice, although protection against anthrax challenge was limited [26]. Initial studies by Galloway et al. demonstrated lack of protection and absence of anti-PA antibodies in rabbits given three inoculations with naked PA63 DNA by gene gun [23]. This failure may be contributed to the use of truncated PA. A subsequent study by Hermanson et al. showed that rabbits immunised with three doses of $1 \mathrm{mg}$ PA83 DNA mixed with Vaxfectin are protected and this is associated with high titers of TNAs [9]. In our experiment, only $50 \mu \mathrm{g}$ of PA83 DNA was used for immunisation and therefore there is scope to improve the immunogenicity of the dendriplex by increasing the amount of PA DNA per injection.

Hahn et al. immunised sheep with three PA83 constructs embedded in Vaxfectin [27]. The construct used in this study (pCMV/ER PA83) gave a suboptimal humoral response compared to a mixture that included a construct that contained PA Domain 4, the part of PA that binds to the cellular receptor [27]. Thus formulation of dendriplexes that contain a PA Domain 4 construct may improve the immunogenicity and efficacy of a PA DNA vaccine further.

The route of administration may also play a role in the induction of TNAs. Boyaka et al. revealed that neutralising antibodies were induced in external secretions of mice following mucosal immunisation with rPA [28].

Consideration should therefore be given to this route of inoculation to improve efficacy of these dendriplex particles as an anthrax vaccine. Other vaccination models such as rhesus macaques, considered to be closest to humans, should be investigated for genetic vaccination with the dendriplex vaccine $[29,30]$. Prior to this, studies in larger animals such as rabbits or sheep will need to be undertaken.

\section{CONCLUSION}

Many attempts have been made to improve the immunogenicity of PA DNA vaccines. Particulate systems and small

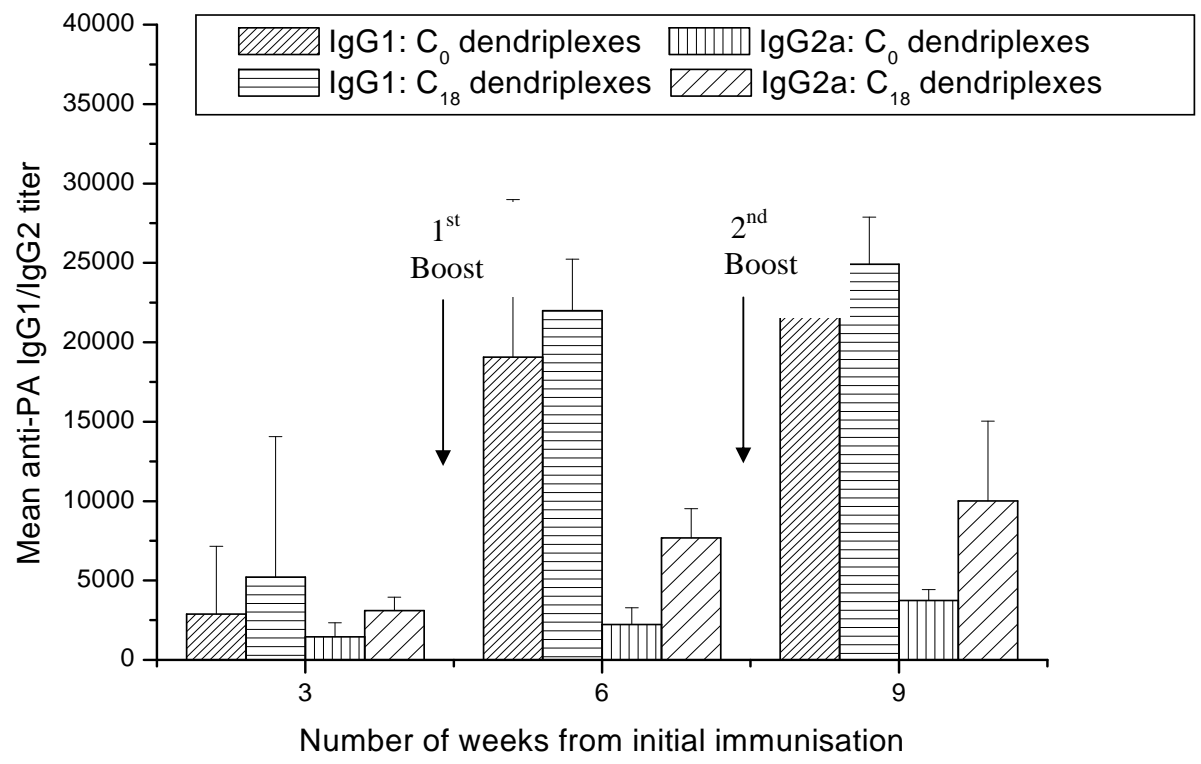

Fig. (5). Mean anti-PA IgG1 and IgG2a antibody levels in BALB/c mice immunised with $\mathrm{C}_{0}$ dendriplexes, and $\mathrm{C}_{18}$ dendriplexes containing $50 \mu \mathrm{g}$ of pCMV/ER PA83. Bars represent SD of five animals. 
peptides have been reported to possess adjuvant properties; therefore we investigated dendriplexes as a potential vehicle to deliver DNA vaccines. Naked PA DNA did not induce an antibody response even after boosting, whereas dendriplexes produced a strong anti-PA antibody response. This confirms our previous results [12]. We show here that the antibody response is dose dependent and dependent on the genetic background of the host, providing opportunities to further optimise the efficacy of a dendriplex DNA vaccine.

Despite improved immunogenicity of dendriplexes with a higher dose of PA83 DNA, TNAs were not produced. Gene gun inoculation of PA DNA did induce TNAs in a minority of immunised mice, although the association with protection was weak $[18,26]$. An important difference with our work is the route of immunisation i.e. intra-dermal by gene gun vs i.m. by dendriplexes. The former route may be more favourable for the induction of functional antibodies and therefore more work needs to be conducted to assert if dendriplexes can induce TNA via the dermal route. In addition, A/J and $\mathrm{BALB} / \mathrm{c}$ mice may not be the ideal hosts for the evaluation of the efficacy of PA vaccines or to determine the induction of TNAs [22]. Subsequent work carried out in sheep showed that a mixture of DNA constructs delivered by Vaxfectin improved the anti-PA antibody response but unfortunately TNA titers were not assessed [27].

In conclusion, this study confirms and extends the usefulness of dendriplexes for the delivery of DNA vaccines. However further work needs to be conducted to asses the potential of dendriplexes to elicit functional antibodies associated with protection (i.e. TNAs), using alternative routes for inoculation, higher doses of DNA, multiple constructs or different animal models.

\section{ACKNOWLEDGEMENTS}

S.J.R received funding support for a $\mathrm{PhD}$ studentship School of Pharmacy. Mr David McCarthy is thanked for assistance with the electron microscopy. We are grateful to Drs Ulrike Hahn and Wolfgang Beyer of the University of Hohenheim (Germany) for the generous gift of bacterial strains that harbour the PA plasmid and the empty vector.

\section{REFERENCES}

[1] Ivins, B.E.; Welkos, S.L. Cloning and expression of the Bacillus anthracis protective antigen gene in Bacillus subtilis. Infect. Immun., 1986, 54 (2), 537-542.

[2] Leppla, S.H.; Robbins, J.B.; Schneerson, R.; Shiloach, J. Development of an improved vaccine for anthrax. J Clin. Invest., 2002, 110 (2), 141-144.

[3] Turnbull, P.C. Anthrax vaccines: past, present and future. Vaccine, 1991, 9 (8), 533-539.

[4] Whiting, G.C.; Rijpkema, S.; Adams, T.; Corbel, M.J. Characterisation of adsorbed anthrax vaccine by two-dimensional gel electrophoresis. Vaccine, 2004, 22 (31-32), 4245-4251.

[5] Casadevall, A. Passive antibody administration (immediate immunity) as a specific defense against biological weapons. Emerg. Infect. Dis., 2002, 8 (8), 833-841.

[6] Pitt, M.L.; Little, S.F.; Ivins, B.E.; Fellows, P.; Barth, J.; Hewetson, J.; Gibbs, P.; Dertzbaugh, M.; Friedlander, A.M. In vitro correlate of immunity in a rabbit model of inhalational anthrax. Vaccine, 2001, 19 (32), 4768-4773.

[7] Little, S.F.; Ivins, B.E.; Fellows, P.F.; Friedlander, A.M. Passive protection by polyclonal antibodies against Bacillus anthracis infection in guinea pigs. Infect. Immun., 1997, 65, 5171-5175.

[8] Brey, R.N. Molecular basis for improved anthrax vaccines. $A d v$. Drug Deliv. Rev., 2005, 57 (9), 1266-92.
[9] Hermanson, G.; Whitlow, V.; Parker, S.; Tonsky, K.; Rusalov, D.; Ferrari, M.; Lalor, P.; Komai, M.; Mere, R.; Bell, M.; Brenneman, K.; Mateczun, A.; Evans, T.; Kaslow, D.; Galloway, D.; Hobart, P. A cationic lipid-formulated plasmid DNA vaccine confers sustained antibody-mediated protection against aerosolized anthrax spores. Proc. Natl. Acad. Sci. USA, 2004, 101 (37), 13601-13606.

[10] Mollenkopf, H.J.; Dietrich, G.; Fensterle, J.; Grode, L.; Diehl, K.D.; Knapp, B.; Singh, M.; O'Hagan, D.T.; Ulmer, J.B.; Kaufmann, S.H. Enhanced protective efficacy of a tuberculosis DNA vaccine by adsorption onto cationic PLG microparticles. Vaccine, 2004, 22 (21-22), 2690-2695.

[11] Xie, H.; Gursel, I.; Ivins, B.E.; Singh, M.; O'Hagan, D.T.; Ulmer, J. B.; Klinman, D.M. CpG Oligodeoxynucleotides adsorbed onto polylactide-co-glycolide microparticles improve the immunogenicity and protective activity of the licensed anthrax vaccine. Infect. Immun., 2005, 73 (2), 828-833.

[12] Ribeiro, S.J.; Rijpkema, S.G.; Durrani, Z.; Florence, A.T. PLGAdendrons enhance immunogenicity of a DNA vaccine against anthrax in mice. Int. J. Pharm., 2007, 331 (2), 228-232.

[13] Svenson, S.; Tomalia, D.A. Dendrimers in biomedical applications-reflections on the field. Adv. Drug Deliv. Rev., 2005, 57, 21062129.

[14] Boas, U.; Heegaard, P.M. Dendrimers in drug research. Chem. Soc. Rev., 2004, 33 (1), 43.

[15] Golan, R.; Pietrasanta, L.I.; Hsieh, W.; Hansma, H.G. DNA toroids: stages in condensation. Biochemistry, 1999, 38 (42), 1406914076.

[16] Lee, C.G.; Choi, S.Y.; Park, S.H.; Park, K.S.; Ryu, S.H.; Sung, Y.C. The synthetic peptide Trp-Lys-Tyr-Met-Val-D-Met as a novel adjuvant for DNA vaccine. Vaccine, 2005, 23 (38), 4703-4710.

[17] Dasgupta, S.; Bhinge, A.; Chandran, V.; Sewlikar, S.; Nimbkar, A.; Datta, D. Role of L-lysine $\mathrm{HCl}$ in immunopotentiation towards development of suitable tuberculosis vaccination. Vaccine, 2003, 21 (32), 4722-4727.

[18] Hahn, U.K.; Alex, M.; Czerny, C.P.; Bohm, R.; Beyer, W. Protection of mice against challenge with Bacillus anthracis STI spores after DNA vaccination. Int. J. Med. Microbiol., 2004, 294 (1), 3544.

[19] Sakthivel, T.; Toth, I,; Florence, A.T. Synthesis and physicochemical properties of lipophilic polyamide dendrimers. Pharm. Res. 1998, 15, 776-782.

[20] Hering, D.; Thompson, W.; Hewetson, J.; Little, S.; Norris, S.; Pace-Templeton, J. Validation of the anthrax lethal toxin neutralization assay. Biologicals, 2004, 32 (1), 17-27.

[21] Williamson, E.D.; Bennett, A.M.; Perkins, S.D.; Beedham, R.J.; Miller, J.; Baillie, L.W. Co-immunisation with a plasmid DNA cocktail primes mice against anthrax and plague. Vaccine, 2002, 20 (23-24), 2933-2941.

[22] Welkos, S.L.; Friedlander, A.M. Pathogenesis and genetic control of resistance to the Sterne strain of Bacillus anthracis. Microb. Pathog., 1988, 4 (1), 53-69.

[23] Galloway, D.R.; Baillie, L. DNA vaccines against anthrax. Expert. Opin. Biol. Ther., 2004, 4 (10), 1661-1667.

[24] Flick-Smith, H.C.; Waters, E.L.; Walker, N.J.; Miller, J.; Stagg, A. J.; Green, M.; Williamson, E.D. Mouse model characterisation for anthrax vaccine development: comparison of one inbred and one outbred mouse strain. Microb. Pathog., 2005, 38 (1), 33-40.

[25] Gu, M.L.; Leppla, S.H.; Klinman, D.M. Protection against anthrax toxin by vaccination with a DNA plasmid encoding anthrax protective antigen. Vaccine, 1999, 17 (4), 340-344.

[26] Hahn, U.K.; Boehm, R.; Beyer, W. DNA vaccination against anthrax in mice-combination of anti-spore and anti-toxin components. Vaccine, 2006, 24 (21), 4569-4571.

[27] Hahn, U.K.; Aichler, M.; Boehm, R.; Beyer, W. Comparison of the immunological memory after DNA vaccination and protein vaccination against anthrax in sheep. Vaccine, 2006, 24 (21), 4595-4597.

[28] Boyaka, P.N.; Tafaro, A.; Fischer, R.; Leppla, S.H.; Fujihashi, K.; McGhee, J.R. Effective mucosal immunity to anthrax: neutralizing antibodies and Th cell responses following nasal immunization with protective antigen. J. Immunol., 2003, 170 (11), 5636-5643.

[29] Ivins, B.E.; Pitt, M.L.; Fellows, P.F.; Farchaus, J.W.; Benner, G.E.; Waag, D.M.; Little, S.F.; Anderson-GW, J.; Gibbs, P.H.; Friedlander, A.M. Comparative efficacy of experimental anthrax vaccine candidates against inhalation anthrax in rhesus macaques. Vaccine, 1998, 16 (11-12), 1141-1148. 
[30] Klinman, D.M.; Xie, H.; Little, S.F.; Currie, D.; Ivins, B.E. CpG oligonucleotides improve the protective immune response induced by the anthrax vaccination of rhesus macaques. Vaccine, 2004, 22 (21-22), 2881-2886.

Received: March 10, 2008

Revised: October 27, 2008

Accepted: October 31, 2008

(C) Ribeiro et al.; Licensee Bentham Open.

This is an open access article licensed under the terms of the Creative Commons Attribution Non-Commercial License (http://creativecommons.org/licenses/by$\mathrm{nc} / 3.0 /$ ) which permits unrestricted, non-commercial use, distribution and reproduction in any medium, provided the work is properly cited. 